\title{
HONORÁRIOS ADVOCATÍCIOS À LUZ DA REFORMA TRABALHISTA (LEI No 13.467/17) ${ }^{1}$
}

ATTORNEY FEES IN LIGHT OF THE LABOR REFORM (LAW NO. 13,467 / 17)

Kaique Souza PEDAES ${ }^{2}$

lara Marthos ÁGUILA ${ }^{3}$

ISSUE DOI: 10.21207/2675-0104.2019.926

\section{RESUMO}

A Lei $\mathrm{n}^{\circ} 13.467 / 17$, que ficou conhecida como Reforma Trabalhista, instituiu no âmbito da Justiça do Trabalho os honorários de sucumbência. O objetivo desta investigação científica é analisar as regras relativas ao tema, bem como refletir suposta inconstitucionalidade do $\$ 4^{\circ}$ do art. 791-A da CLT, que autoriza a cobrança de honorários de beneficiário da justiça gratuita. Para tanto, utilizou-se das pesquisas bibliográfica e documental. Com o trabalho, encontrou-se convergência entre doutrinadores quanto a hipótese de honorários de sucumbência recíproca, ao passo que se observou divergência no Supremo Tribunal Federal, e em diferentes instâncias da Justiça do Trabalho, sobre a cobrança de honorários de beneficiário da justiça gratuita.

Palavras-chave: Advogado. CLT. Honorários. Reforma Trabalhista. Sucumbência.

\footnotetext{
${ }^{1} \mathrm{O}$ presente artigo sintetiza a monografia de conclusão da pesquisa, realizada para o Programa Interno de Bolsas de Iniciação Científica (PIBIC 2018-2019) da Faculdade de Direito de Franca (FDF), Franca/SP.

${ }^{2}$ Discente da Faculdade de Direito de Franca (FDF), Franca/SP. Bolsista do Programa Interno de Bolsas de Iniciação Científica (PIBIC 2018-2019).

${ }^{3}$ Doutoranda em Direito pela Fadisp. Mestre em Direito pela Universidade Estadual Paulista Júlio de Mesquita Filho - Unesp (1998). Graduada em Direito pela Universidade Estadual Paulista Júlio de Mesquita Filho - Unesp (1990). Professora titular da Faculdade de Direito de Franca, na disciplina Direito do Trabalho. Professora substituta na Universidade Estadual Paulista Júlio de Mesquita Filho - Unesp, campus de Franca (2009 a 2013). Advogada trabalhista atuante. Currículo Lattes: http://lattes.cnpq.br/0671409528318178.
} 


\begin{abstract}
The Law n. 13.467/17, which became known as the Labor Reform, established the succumbence fees in the area of Labor Justice. The objective of this scientific investigation is to analyze the rules related to the theme, as well as to reflect the supposed unconstitutionality of the $\$ 4^{\circ}$ of the art. 791-A of the CLT, which authorizes the charge of fees of beneficiary of free justice. To do so, it was used the bibliographic and documentary research. With the work, it was found convergence between authors regarding the hypothesis of reciprocal succumbent fees, while there was disagreement in the Supreme Federal Court, and in different instances of the Labor Justice, about the charge of fees of beneficiary of free justice.
\end{abstract}

Keywords: Attorney. CLT. Fees. Labor Reform.

Em 11 de novembro de 2017, entrou em vigor a Lei ${ }^{\circ}$ 13.467/17, que ficou conhecida como Reforma Trabalhista. Responsável por promover diversas alterações na Consolidação das Leis do Trabalho, que impactaram a vida de trabalhadores, empregadores e do próprio Estado, a reforma deu início a discussões bem antes do início de sua vigência, em especial pela instituição dos honorários de sucumbência na Justiça do Trabalho, um tema controverso, merecedor de um estudo crítico e analítico a seu respeito, sendo o objeto desta investigação.

Sancionada pelo então Presidente da República Michel Temer em 13 de julho daquele ano, rapidamente a nova lei foi alvo de diversas ações diretas de inconstitucionalidade. Uma dessas ADIs impugnava, além de outros dispositivos, aquele que autoriza a cobrança de honorários de sucumbência até mesmo de beneficiário da justiça gratuita, com a utilização de créditos obtidos pelo beneficiário em juízo ( $\$ 4^{\circ}$ do art. 791-A da CLT).

Esta regra é considerada pela Procuradoria-Geral da República e por diversos doutrinadores como incompatível com a Constituição Federal, por violar, dentre outros, os direitos de acesso à Justiça e de assistência judiciária integral e gratuita.

Assim, esta investigação tem, como um de seus objetivos, abordar os argumentos jurídicos utilizados pela PGR e por doutrinadores, além dos mencionados por magistrados em decisões de diferentes instâncias do Poder Judiciário, para defender a constitucionalidade, ou não, da cobrança de honorários sucumbenciais de beneficiário da justiça gratuita. 
A pesquisa bibliográfica, representada pelo levantamento de referências teóricas já analisadas e publicadas por meios escritos e eletrônicos, como livros e páginas de web sites, tem inegável contribuição para o desenvolvimento deste trabalho. Todavia, esta investigação científica não poderia atingir seus objetivos valendo-se somente deste procedimento.

Utiliza-se também da pesquisa documental, por meio da qual são analisadas decisões proferidas por Tribunais Regionais do Trabalho e por uma turma do Tribunal Superior do Trabalho acerca do tema, e se acompanha o andamento da Ação Direta de Inconstitucionalidade n ${ }^{\circ} 5.766$ no Supremo Tribunal Federal.

\section{DO CABIMENTO DOS HONORÁRIOS DE SUCUMBÊNCIA NA JUSTIÇA DO TRABALHO}

Mesmo antes do advento da Lei $n^{\circ} 13.467 / 17$ os honorários sucumbenciais na Justiça do Trabalho eram devidos. Todavia, apenas em casos específicos, e não decorriam da mera sucumbência - como é agora , mas da cumulação de alguns requisitos, presentes na Súmula 219 do TST, a seguir transcrita:

HONORÁRIOS ADVOCATÍCIOS. CABIMENTO (alterada a redação do item I e acrescidos os itens IV a VI em decorrência do CPC de 2015) - Res. 204/2016, DEJT divulgado em 17, 18 e 21.03.2016

I - Na Justiça do Trabalho, a condenação ao pagamento de honorários advocatícios não decorre pura e simplesmente da sucumbência, devendo a parte, concomitantemente: a) estar assistida por sindicato da categoria profissional; b) comprovar a percepção de salário inferior ao dobro do salário mínimo ou encontrar-se em situação econômica que não lhe permita demandar sem prejuízo do próprio sustento ou da respectiva família. (art. 14, $\S 1^{\circ}$, da Lei $n^{\circ} 5.584 / 1970$ ). (ex-OJ $n^{\circ} 305$ da SBDI-I).

II - É cabível a condenação ao pagamento de honorários advocatícios em ação rescisória no processo trabalhista.

III - São devidos os honorários advocatícios nas causas em que o ente sindical figure como substituto processual e nas lides que não derivem da relação de emprego.

IV - Na ação rescisória e nas lides que não derivem de relação de emprego, a responsabilidade pelo pagamento dos honorários advocatícios da sucumbência submete-se à disciplina do Código de Processo Civil (arts. 85, 86, 87 e 90).

V - Em caso de assistência judiciária sindical ou de substituição processual sindical, excetuados os processos em que a Fazenda 
Pública for parte, os honorários advocatícios são devidos entre o mínimo de dez e o máximo de vinte por cento sobre o valor da condenação, do proveito econômico obtido ou, não sendo possível mensurá-lo, sobre o valor atualizado da causa (CPC de 2015, art. $\left.85, \S 2^{\circ}\right)$.

VI - Nas causas em que a Fazenda Pública for parte, aplicar-se-ão os percentuais específicos de honorários advocatícios contemplados no Código de Processo Civil.

Da leitura do item I da súmula, depreende-se que, para que o vencido fosse condenado ao pagamento dos honorários do advogado do vencedor, não era suficiente a mera sucumbência, isto é, a rejeição de um ou mais pedidos formulados no processo; era preciso a cumulação de dois requisitos.

Em primeiro lugar, a parte deveria "estar assistida por sindicato da categoria profissional". Ademais, era necessário comprovar uma das duas situações a seguir: que a parte recebia salário inferior ao dobro do salário mínimo, ou que a parte se encontrava em situação econômica que não lhe permitia demandar sem prejuízo do próprio sustento ou da respectiva família.

Com a sucumbência e a presença destes dois requisitos, haveria a condenação ao pagamento dos honorários, que seriam revertidos em favor do sindicato assistente, conforme art. 16 da Lei $\mathrm{n}^{\circ}$ 5.584/1970 (atualmente revogado). Por ausência de previsão legal, não era possível a condenação do empregado, ou do sindicato que o representasse, na verba honorária ${ }^{4}$.

Na ação rescisória, por sua vez, a mera sucumbência bastava para que a parte vencida fosse condenada ao pagamento dos honorários, conforme os itens II e IV da Súmula 219 (salvo se beneficiária da justiça gratuita).

Com a inclusão do art. 791-A na CLT feita pela Lei $n^{\circ}$ 13.467/17, os honorários sucumbenciais passaram a ser devidos em todos os casos pela mera sucumbência. Cumpre transcrever o novel artigo em sua integralidade:

Art. 791-A. Ao advogado, ainda que atue em causa própria, serão devidos honorários de sucumbência, fixados entre o mínimo de 5\% (cinco por cento) e o máximo de $15 \%$ (quinze por cento) sobre o

\footnotetext{
${ }^{4}$ DESIDERI, Susy Lani. Dicionário jurisprudencial de decisões trabalhistas - volume I. Julex, 1998, p. 419.
} 
valor que resultar da liquidação da sentença, do proveito econômico obtido ou, não sendo possível mensurá-lo, sobre o valor atualizado da causa.

$\S 1^{\circ}$ Os honorários são devidos também nas ações contra a Fazenda Pública e nas ações em que a parte estiver assistida ou substituída pelo sindicato de sua categoria.

$\S 2^{\circ}$ Ao fixar os honorários, o juízo observará:

I - o grau de zelo do profissional;

II - o lugar de prestação do serviço;

III - a natureza e a importância da causa;

IV - o trabalho realizado pelo advogado e o tempo exigido para o seu serviço.

$\S 3^{\circ} \mathrm{Na}$ hipótese de procedência parcial, o juízo arbitrará honorários de sucumbência recíproca, vedada a compensação entre os honorários.

$\S 4^{\circ}$ Vencido o beneficiário da justiça gratuita, desde que não tenha obtido em juízo, ainda que em outro processo, créditos capazes de suportar a despesa, as obrigações decorrentes de sua sucumbência ficarão sob condição suspensiva de exigibilidade e somente poderão ser executadas se, nos dois anos subsequentes ao trânsito em julgado da decisão que as certificou, o credor demonstrar que deixou de existir a situação de insuficiência de recursos que justificou a concessão de gratuidade, extinguindo-se, passado esse prazo, tais obrigações do beneficiário.

$\S 5^{\circ}$ São devidos honorários de sucumbência na reconvenção.

No processo civil, "os honorários serão fixados entre o mínimo de dez e o máximo de vinte por cento sobre o valor da condenação, do proveito econômico obtido ou, não sendo possível mensurá-lo, sobre o valor atualizado da causa", conforme art. $85, \S 2^{\circ}$ do CPC.

No processo trabalhista, por sua vez, a fixação será "entre o mínimo de 5\% (cinco por cento) e o máximo de $15 \%$ (quinze por cento) sobre o valor que resultar da liquidação da sentença, do proveito econômico obtido ou, não sendo possível mensurá-lo, sobre o valor atualizado da causa", conforme o caput do art. 791-A da CLT.

Apesar de a porcentagem ser diferente no processo civil e no processo trabalhista - o que representa discriminação ao profissional que atua na Justiça Especializada ${ }^{5}$-, em qualquer dos casos o juiz observará, ao fixar os honorários, os mesmos critérios, presentes no art. $85, \S 2^{\circ}$, I a IV do CPC, e no art. 791-A, §2º I a IV da CLT.

"Os honorários são devidos também nas ações contra a Fazenda Pública e nas ações em que a parte estiver assistida ou substituída pelo

\footnotetext{
${ }^{5}$ CASSAR, Vólia Bomfim; BORGES, Leonardo Dias. Comentários à reforma trabalhista. 1. ed. São Paulo: Método, 2017, p. 99.
} 
sindicato de sua categoria" (art. 791-A, $§ 1^{\circ}$ da CLT). Nas ações em que a parte estiver assistida ou substituída pelo sindicato de sua categoria, os honorários serão destinados ao advogado que houver atuado na causa, e não mais ao sindicato (o art. 16 da Lei $\mathrm{n}^{\circ} 5.584 / 70$, que previa o sindicato como destinatário dos honorários, foi expressamente revogado pela Lei $\mathrm{n}^{\circ}$ 13.725/18).

Determina o $\S 3^{\circ}$, do art. 791-A, que "na hipótese de procedência parcial, o juízo arbitrará honorários de sucumbência recíproca, vedada a compensação entre os honorários". Mauro Schiavi defende que a sucumbência (derrota) a justificar a condenação ao pagamento de honorários advocatícios é a rejeição total dos pedidos, ou de algum destes. Não basta a rejeição apenas em parte de um dos pedidos.

Exemplificando, se o reclamante fizer os pedidos A, B, C e D, e sucumbir apenas em parte no pedido A, "que se refere a horas extras, já que a jornada acolhida pelo juízo foi inferior à declinada na inicial, não haverá sucumbência recíproca a justificar honorários advocatícios ao reclamado" .

Neste sentido, está o Enunciado $n^{\circ} 99$ da $2^{\text {a }}$ Jornada de Direito Material e Processual do Trabalho, evento promovido pela Anamatra (Associação Nacional dos Magistrados da Justiça do Trabalho) em outubro de 2017 para debater temas relativos à Reforma Trabalhista ${ }^{7}$ :

\begin{abstract}
Enunciado $\mathrm{n}^{\circ} 99$ - Sucumbência recíproca - O juízo arbitrará honorários de sucumbência recíproca (art. 791-A, §3º da CLT) apenas em caso de indeferimento total do pedido específico. $\mathrm{O}$ acolhimento do pedido, com quantificação inferior ao postulado, não caracteriza sucumbência parcial, pois a verba postulada restou acolhida. Quando o legislador mencionou "sucumbência parcial", referiu-se ao acolhimento de parte dos pedidos formulados na petição inicial.
\end{abstract}

Portanto, imaginando que o reclamante pleiteie indenização por dano extrapatrimonial no valor de $\mathrm{R} \$ 10.000,00$ e o juízo lhe defira apenas $\mathrm{R} \$ 5.000,00$, não haverá arbitramento de honorários de sucumbência recíproca.

\footnotetext{
${ }^{6}$ SCHIAVI, Mauro. A reforma trabalhista e o processo do trabalho: aspectos processuais da Lei n. 13.467/17. 1. ed. São Paulo: LTr Editora, 2017, p. 84.

${ }^{7}$ ANAMATRA. Reforma trabalhista: Anamatra divulga íntegra dos enunciados aprovados na 2 Jornada. 19 de outubro de 2017. Disponível em: $<$ https://www.anamatra.org.br/imprensa/noticias/25797-reforma-trabalhista-anamatra-divulgaintegra-dos-enunciados-aprovados-na-2-jornada>. Acesso em: 05 fev. 2019.
} 
A expressão "procedência parcial" referida no $\S^{\circ}$ do art. 791-A (e não "sucumbência parcial", como consta da parte final do enunciado acima em comento) não significa acolhimento parcial de um pedido, mas, sim, acolhimento de parte dos pedidos (um pedido deferido e um pedido rejeitado, por exemplo). Conclui-se que os honorários de advogado somente podem ser exigidos se o reclamante for totalmente sucumbente em um determinado pedido, e não no caso de o pedido não ter sido acolhido em sua totalidade.

É a mesma sistemática da Súmula 326 do STJ: "Na ação de indenização por dano moral, a condenação em montante inferior ao postulado na inicial não implica sucumbência recíproca".

Ainda sobre o tema sucumbência recíproca, dispõe o parágrafo único do art. 86 do CPC, aplicável ao processo do trabalho ${ }^{8}$, que "se um litigante sucumbir em parte mínima do pedido, o outro responderá, por inteiro, pelas despesas e pelos honorários".

Por fim, a compensação entre os honorários não é possível pois eles pertencem ao advogado, e não às partes. Assim, se cada parte deve $\mathrm{R} \$$ $1.000,00$ ao advogado da outra, por exemplo, estes créditos não se anulam. Cada profissional terá direito a receber sua verba.

O parágrafo seguinte, o quarto do art. 791-A, é ainda mais polêmico, havendo discussão a respeito de sua constitucionalidade. Assim, fica reservado o tópico seguinte deste trabalho para sua análise.

O quinto e último parágrafo do art. 791-A determina que "são devidos honorários de sucumbência na reconvenção". Mas, e nas fases de cumprimento de sentença, execução e recursos? Também serão devidos honorários advocatícios de sucumbência?

Correia e Miessa entendem, a nosso ver corretamente, que a reforma não foi omissa. O seu silêncio é eloquente. Se o legislador quisesse prever o cabimento dos honorários nestes casos, bastaria adicionar mais palavras ao art. 791-A, $\S 5^{\circ}$ da CLT. Mas, não. Ele decidiu por tratar apenas da reconvenção, que tem natureza de nova ação ${ }^{9}$.

\footnotetext{
${ }^{8}$ CORREIA, Henrique; MIESSA, Élisson. Manual da reforma trabalhista: o que mudou? 1. ed. Salvador: Editora JusPodivm, 2018, p. 746.

${ }^{9}$ CORREIA, Henrique; MIESSA, Élisson. Manual da reforma trabalhista: o que mudou? 1. ed. Salvador: Editora JusPodivm, 2018, p. 740.
} 


\title{
3 DA (IN) CONSTITUCIONALIDADE DA COBRANÇA DE HONORÁRIOS SUCUMBENCIAIS DE BENEFICIÁRIO DA JUSTIÇA GRATUITA
}

O quarto parágrafo é, sem dúvidas, o mais polêmico do art. 791A da CLT. Alvo de uma ação no STF, que questiona a sua constitucionalidade, o dispositivo autoriza que sejam cobrados honorários de sucumbência de beneficiário da justiça gratuita em caso de derrota no processo, como se vê:

\begin{abstract}
$\S 4^{\circ}$ Vencido o beneficiário da justiça gratuita, desde que não tenha obtido em juízo, ainda que em outro processo, créditos capazes de suportar a despesa, as obrigações decorrentes de sua sucumbência ficarão sob condição suspensiva de exigibilidade e somente poderão ser executadas se, nos dois anos subsequentes ao trânsito em julgado da decisão que as certificou, o credor demonstrar que deixou de existir a situação de insuficiência de recursos que justificou a concessão de gratuidade, extinguindo-se, passado esse prazo, tais obrigações do beneficiário.
\end{abstract}

Pela leitura do dispositivo legal, entende-se que a concessão da gratuidade da justiça não afasta a responsabilidade do beneficiário pelos honorários advocatícios decorrentes de sua sucumbência. Contudo, eles só poderão ser cobrados em duas hipóteses:

a) se, nos dois anos subsequentes ao trânsito em julgado da decisão que condenou o beneficiário a pagar honorários de sucumbência, o credor demonstrar que deixou de existir a situação de insuficiência de recursos que justificou a concessão de gratuidade. Nesta situação, passado o prazo de dois anos sem alteração na situação financeira do beneficiário, as obrigações decorrentes da sucumbência serão extintas. Há diferença da sistemática processual civil, que estabelece prazo de cinco anos (art. 98, $\S 3^{\circ}$ do $\mathrm{CPC}$ );

b) se o beneficiário tiver obtido em juízo, no mesmo ou em outro processo, créditos capazes de suportar os honorários de sucumbência, caso em que, dos créditos a serem recebidos pelo beneficiário, será descontado o valor a ser pago a título de honorários de sucumbência. A discussão quanto a constitucionalidade fica em torno desta hipótese. 
Correia e Miessa ${ }^{10}$ argumentam que, para o $\S^{\circ}$ do art. 791-A ser considerado constitucional, é necessária a presença, no caso concreto, de dois requisitos cumulativos.

Em primeiro lugar, "o crédito já deve existir no momento da decisão judicial, impedindo decisão condicionada ao recebimento de créditos futuros, até porque a sentença deve ser certa e exigível" ${ }^{11}$.

Em segundo, o crédito recebido em juízo tem de ser capaz de retirar a condição de beneficiário do sucumbente. Ou seja, com o recebimento das verbas, é necessário que tenha deixado de existir a situação de insuficiência de recursos que justificou a concessão de gratuidade.

Caso se aplique o dispositivo literalmente (recebimento de "créditos capazes de suportar a despesa"), sem considerar se tais créditos não atingem o próprio sustento do beneficiário ou de sua família, explicam os autores que haverá violação aos princípios do acesso à Justiça (art. $5^{\circ}$, LXXIV da Constituição - "a lei não excluirá da apreciação do Poder Judiciário lesão ou ameaça a direito") e da igualdade material (art. $5^{\circ}$, caput da CF).

Justificativas semelhantes foram utilizadas pela ProcuradoriaGeral da República (PGR) ao propor, em 24 de agosto de 2017, antes mesmo da entrada em vigor da reforma, a Ação Direta de Inconstitucionalidade $\mathrm{n}^{\circ} 5.766$, que impugna, dentre outros dispositivos, o $\S 4^{\circ}$ do art. 791-A, da CLT.

De início, importante deixar claro que a PGR entende ser compatível com a Constituição a instituição dos honorários de sucumbência na Justiça do Trabalho. O que se impugna é apenas a expressão "desde que não tenha obtido em juízo, ainda que em outro processo, créditos capazes de suportar a despesa", constante do $\S 4^{\circ}$, pois ela impõe "restrições inconstitucionais à garantia de gratuidade judiciária aos que comprovem insuficiência de recursos" ${ }^{\prime 2}$.

\footnotetext{
${ }^{10}$ CORREIA, Henrique; MIESSA, Élisson. Manual da reforma trabalhista: o que mudou? 1. ed. Salvador: Editora JusPodivm, 2018, p. 750.

${ }^{11}$ Id., Ibid., p. 750.

${ }^{12}$ PROCURADORIA-GERAL DA REPÚBLICA. Ação direta de inconstitucionalidade $\mathbf{n}^{\circ} \mathbf{5 . 7 6 6 .}$ Brasília, 24 de agosto de 2017. Disponível em:

〈http://www.mpf.mp.br/pgr/documentos/ADI5766reformatrabalhista.pdf〉. p. 3. Acesso em: 31 mar. 2019.
} 
Caso esta expressão não existisse, a regra de cobrança de honorários de beneficiário da justiça gratuita na seara trabalhista seria igual à Justiça Comum (a diferença ficaria apenas por conta do prazo em que as obrigações decorrentes da sucumbência ficariam sob condição suspensiva de exigibilidade, que no CPC é de cinco anos e na CLT é de dois).

Até a conclusão deste trabalho, o julgamento da ADI no 5.766 no STF teve somente dois votos: o do Relator Ministro Luis Roberto Barroso e do Ministro Luiz Edson Fachin, com posições divergentes.

Não há data para o retorno do julgamento e, enquanto a Corte não se pronuncia definitivamente, alguns TRTs pelo Brasil e turmas do TST têm proferido suas decisões quanto a validade da norma.

O TRT da $13^{a}$ Região (Estado da Paraíba) considera que o dispositivo em análise não fere a Lei Maior, de modo que permanecerá sendo aplicado até que o STF decida o contrário ${ }^{13}$.

Por sua vez, o TRT da 19 ${ }^{\text {a }}$ Região (Estado de Alagoas), em um incidente de arguição de inconstitucionalidade, deixou de aplicar a norma (a decisão só produz efeitos entre partes envolvidas naquele processo), declarando o seguinte:

[...] Se o art. 791-A da CLT, incluído pela Lei no 13.467/17, impõe restrições às garantias fundamentais de assistência jurídica integral e gratuita (art. $5^{\circ}$, LXXIV) e do acesso à Justiça (art. $5^{\circ}, \mathrm{XXXV),}$ afrontando também o princípio da dignidade da pessoa humana (art. $1^{\circ}, \mathrm{III}$ ), além de dar, equivocadamente, o mesmo tratamento a quem se encontra materialmente em situações desiguais, numa clara violação ao princípio constitucional da igualdade (art. $5^{\circ}$, caput), resta ao Poder Judiciário declarar a sua inconstitucionalidade ${ }^{14}$.

Estas justificativas estão na mesma linha do alegado pela PGR na ADI $n^{\circ} 5.766$ e no voto do Ministro Fachin, que concorda com a inconstitucionalidade da norma discutida.

\footnotetext{
${ }^{13}$ PARAÍBA. Tribunal Regional do Trabalho da $13^{\mathrm{a}}$ Região. Acórdão. Proc. 0000628-

32.2018.5.13.0014. Relatora Ana Maria Ferreira Madruga. João Pessoa, 25 de março de 2019.

Disponível em: <https://trt-13.jusbrasil.com.br/jurisprudencia/692142724/recurso-ordinario-emprocedimento-sumarissimo-ro-6283220185130014-0000628-3220185130014>. Acesso em: 31 mar. 2019.

${ }^{14}$ ALAGOAS. Tribunal Regional do Trabalho da $19^{\text {a }}$ Região. Proc. 0000206-34.2018.5.19.0000.

Relator João Leite de Arruda Alencar. Maceió, 07 de novembro de 2018. Disponível em:

〈https://www.legale.com.br/uploads/e54ca30dcd387a194454664527df3a6a.pdf〉. Acesso em: 31 mar. 2019.
} 
A PGR alega que a garantia de assistência jurídica integral e gratuita (art. $5^{\circ}$, LXXIV da CF) foi restringida pelo $\S 4^{\circ}$ do art. 791-A da CLT e que isso não poderia ocorrer, pois este direito é uma "prerrogativa básica essencial à viabilização de direitos fundamentais, constitui veículo de garantia do mínimo existencial e assume [...] caráter extremo de direito irredutível" $"$.

Sendo um direito irredutível, a lei não poderia impor ao beneficiário da justiça gratuita o pagamento de honorários sem estar "afastada a condição de pobreza que justificou o benefício"16, afinal, isto representaria uma redução de um direito que, aduz a PGR, é irredutível. Todavia, foi exatamente o que a Reforma Trabalhista fez, o que representaria, por consequência, violações a outros direitos, como o do acesso à Justiça e o da igualdade, além do princípio da dignidade da pessoa humana.

Enquanto o Ministro Fachin votou pela procedência da ação, o Relator Ministro Barroso optou por dar interpretação conforme à Constituição ao $\$ 4^{\circ}$ do art. 791-A da CLT. Ele defendeu que o direito de gratuidade judiciária pode ser regulado de forma a desincentivar a litigância abusiva, dizendo:

As normas processuais podem e devem criar uma estrutura de incentivos e desincentivos que seja compatível com os limites de litigiosidade que a sociedade comporta. $\mathrm{O}$ descasamento entre $\mathrm{o}$ custo individual de postular em juízo e o custo social da litigância faz com que o volume de ações siga uma lógica contrária ao interesse público. A sobreutilização do Judiciário congestiona o serviço, compromete a celeridade e a qualidade da prestação da tutela jurisdicional, incentiva demandas oportunistas e prejudica a efetividade e a credibilidade das instituições judiciais. Vale dizer: afeta, em última análise, o próprio direito constitucional de acesso à Justiça ${ }^{17}$.

\footnotetext{
${ }^{15}$ PROCURADORIA-GERAL DA REPÚBLICA. Ação direta de inconstitucionalidade $\mathbf{n}^{\circ} \mathbf{5 . 7 6 6 .}$ Brasília, 24 de agosto de 2017. Disponível em: <http://www.mpf.mp.br/pgr/documentos/ADI5766reformatrabalhista.pdf >. p. 33. Acesso em: 31 mar. 2019.

${ }^{16}$ PROCURADORIA-GERAL DA REPÚBLICA. Ação direta de inconstitucionalidade $\mathbf{n}^{0} \mathbf{5 . 7 6 6 .}$ Brasília, 24 de agosto de 2017. Disponível em: <http://www.mpf.mp.br/pgr/documentos/ADI5766reformatrabalhista.pdf>. p. 15. Acesso em: 31 mar. 2019.

${ }^{17}$ BARROSO, Luis Roberto. Ementa do voto na ação direta de inconstitucionalidade $\mathbf{n}^{\mathbf{0}} \mathbf{5 . 7 6 6 .}$ Brasília, 10 de maio de 2018. Disponível em: <https://www.conjur.com.br/dl/ementa-voto-barrosocustas-processos.pdf>. Acesso em: 31 mar. 2019.
} 
Disse ainda que a cobrança de honorários de beneficiário da justiça gratuita é um "mecanismo legítimo de desincentivo ao ajuizamento de demandas ou de pedidos aventureiros" $"$.

Contudo, ao passo que o dispositivo inserido na CLT pela reforma permite que quaisquer verbas obtidas pelo beneficiário em outro processo sejam utilizadas para o pagamento de honorários, Barroso votou para limitar a utilização destes valores, da seguinte maneira:

[...] A cobrança de honorários sucumbenciais poderá incidir: (i)
sobre verbas não alimentares, a exemplo de indenizações por danos
morais, em sua integralidade; (ii) sobre o percentual de até $30 \%$ do
valor que exceder ao teto do Regime Geral de Previdência Social,
quando pertinentes a verbas remuneratórias $[\ldots]^{19}$.

Portanto, se o beneficiário tiver obtido verbas não alimentares em outro processo, elas poderão ser utilizadas em sua integralidade para o pagamento de honorários. Mas, se forem verbas remuneratórias, só poderão ser usadas se superiores ao teto da Previdência Social (R \$ 5.839,45 em 2019), e apenas sobre o percentual de até $30 \%$ do valor que exceder ao teto (exemplificando: se o valor que exceder ao teto for $\mathrm{R} \$ 1.000,00$, somente R\$ 300,00 poderão ser empregados para o pagamento de honorários).

O assunto chegou ao Tribunal Superior do Trabalho em maio de 2019 e a $3^{\text {a }}$ Tuma proferiu decisão, sem efeito vinculante, considerando constitucional a cobrança de honorários advocatícios de beneficiário da justiça gratuita. Em seu voto, o Relator Ministro Alberto Bresciani adotou posição semelhante à dos defensores da norma, ao explicar que "a imposição pelo legislador de honorários sucumbenciais ao reclamante reflete a intenção de desestimular lides temerárias. É uma opção política" ${ }^{20}$.

Todavia, o ministro não aplicou o $\$ 4^{\circ}$ do art. 791-A de forma literal. Em seu voto, argumentou "que só será exigido do beneficiário da Justiça gratuita o pagamento de honorários advocatícios se ele obtiver créditos suficientes, neste ou em outro processo, para retirá-lo da condição de miserabilidade" ${ }^{21}$. O dispositivo inserido pela Reforma Trabalhista na

\footnotetext{
${ }^{18}$ Ib., Ibid.

${ }^{19} \mathrm{Ib}$., Ibid.

${ }^{20}$ BRASIL. Tribunal Superior do Trabalho. Acórdão. Processo no TST-AIRR-2054-
}

06.2017.5.11.0003. Relator Ministro Alberto Bresciani. Brasília, 28 de maio de 2019. Disponível em: <https://www.migalhas.com.br/arquivos/2019/7/art20190716-06.pdf>. Acesso em: 21 jul. 2019.

${ }^{21}$ Id., Ibid. 
CLT, contudo, não condiciona o pagamento dos honorários à existência de créditos suficientes para retirar o beneficiário da condição de miserabilidade. Basta que existam créditos trabalhistas capazes de suportar a despesa (os honorários), ainda que subsista a condição de insuficiência de recursos. A decisão da $3^{\mathrm{a}}$ Turma do TST parece ter tentado interpretar o $\S 4^{\circ}$ do art. 791-A conforme a Constituição, e não literalmente.

Enquanto não há o retorno do julgamento deste assunto no STF, a insegurança jurídica no País permanece. Pesquisas nos bancos de dados dos órgãos da Justiça do Trabalho revelam que há grande divergência entre os magistrados. As decisões mencionadas ao longo deste capítulo comprovam isso.

Aqueles que consideram ser o art. 791-A, $\$ 4^{\circ}$ da CLT inconstitucional tem, como assegura o ordenamento jurídico, declarado, de forma difusa, a inconstitucionalidade da norma. Todavia, deve-se temer a conduta daqueles que deixam de aplicar a Reforma Trabalhista integralmente por considerarem a novel legislação "formal e materialmente ilegítima", sem, contudo, declararem a lei incompatível com a Constituição.

Situações como esta demonstram a urgente necessidade de o STF decidir sobre a constitucionalidade das regras trazidas pela Reforma Trabalhista, pois, enquanto isso não ocorrer, os mais prejudicados pela insegurança jurídica serão os próprios trabalhadores, que ingressarão em juízo sem a certeza dos ônus que poderão ter de suportar - ou que, talvez, sequer ingressarão em juízo.

\section{CONSIDERAÇÕES FINAIS}

Com esta investigação, foi possível constatar que a Reforma Trabalhista assegurou aos advogados que atuam em demandas trabalhistas o que já era garantido àqueles atuam em demandas cíveis: o direito ao recebimento de honorários sucumbenciais, que passaram a ser devidos na seara laboral pela mera sucumbência, sem a necessidade de cumulação de quaisquer requisitos, como era antes da entrada em vigor da reforma.

No entanto, o principal objetivo da Lei $\mathrm{n}^{\circ} 13.467 / 17$ com a inserção do art. 791-A na CLT era outro: diminuir o número de ações na Justiça do Trabalho. E isso de fato ocorreu - contudo, segundo a 
Procuradoria-Geral da República, violando direitos constitucionalmente previstos.

Assim, mesmo dois anos depois de sua aprovação pelo Congresso Nacional, a Reforma Trabalhista segue gerando muitas discussões, as quais parecem longe de chegarem ao fim. Deste modo, o caráter de provisoriedade, característico da ciência, está, inevitavelmente, presente neste trabalho. Acompanhando a condição de provisoriedade, há a insegurança jurídica.

Uma das razões para esta insegurança é o fato de o Supremo Tribunal Federal, responsável pelo julgamento das ações diretas de inconstitucionalidade que questionam dispositivos inseridos pela reforma na CLT, como a cobrança de honorários de sucumbência de beneficiário da justiça gratuita, não ter dado um ponto final no assunto.

Independentemente de declarar constitucionais ou inconstitucionais as novas regras, é importante que o STF decida as ações referentes à Reforma Trabalhista brevemente. A urgência é tamanha que a ADI $n^{\circ}$ 5.766, que tem por objeto, dentre outros dispositivos, o art. 791-A, $\S 4^{\circ}$ da CLT, foi ajuizada antes mesmo de ter entrado em vigor a reforma.

A morosidade da Suprema Corte faz com que juízes de primeira instância, tribunais regionais do trabalho e turmas do Tribunal Superior do Trabalho profiram decisões divergentes, gerando, no País, uma nefasta insegurança jurídica. Com isso, os trabalhadores são severamente prejudicados, afinal, não existe certeza quanto aos ônus que eles deverão suportar em caso de sucumbência no processo, o que inibe o ajuizamento de novas demandas, muitas vezes necessárias para a garantia de direitos básicos.

As dúvidas quanto a constitucionalidade do art. 791-A, $\S^{\circ}$ da CLT, e também quanto ao modo correto de serem impostos honorários de sucumbência recíproca aos litigantes, por exemplo, fazem com que o caráter de provisoriedade esteja intrinsecamente presente nesta pesquisa mas, com a insegurança jurídica na bagagem, preferível seria se a provisoriedade não existisse.

\section{REFERÊNCIAS BIBLIOGRÁFICAS}


ALAGOAS. Tribunal Regional do Trabalho da 19a Região. Proc. 0000206-

34.2018.5.19.0000. Relator João Leite de Arruda Alencar. Maceió, 07 de novembro de 2018. Disponível em: <https://bit.ly/2Ze11vO>. Acesso em: 31 mar. 2019.

ANAMATRA. Reforma trabalhista: Anamatra divulga íntegra dos enunciados aprovados

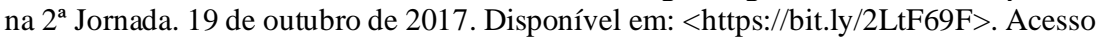
em: 05 fev. 2019.

BARROSO, Luis Roberto. Ementa do voto na ação direta de inconstitucionalidade $\mathrm{n}^{\circ}$ 5.766. Brasília, 10 de maio de 2018. Disponível em: <https://bit.ly/2tgVB1d >. Acesso em: 31 mar. 2019.

BRASIL. Tribunal Superior do Trabalho. Acórdão. Processo n ${ }^{\circ}$ TST-AIRR-205406.2017.5.11.0003. Relator Ministro Alberto Bresciani. Brasília, 28 de maio de 2019. Disponível em: 〈https://bit.ly/2KOTr1R>. Acesso em: 21 jul. 2019.

CASSAR, Vólia Bomfim; BORGES, Leonardo Dias. Comentários à reforma trabalhista. 1. ed. São Paulo: Método, 2017.

CORREIA, Henrique; MIESSA, Élisson. Manual da reforma trabalhista: o que mudou? 1. ed. Salvador: Editora JusPodivm, 2018.

DESIDERI, Susy Lani. Dicionário jurisprudencial de decisões trabalhistas - volume I. Julex, 1998.

PARAÍBA. Tribunal Regional do Trabalho da $13^{\mathrm{a}}$ Região. Acórdão. Proc. 000062832.2018.5.13.0014. Relatora Ana Maria Ferreira Madruga. João Pessoa, 25 de março de 2019. Disponível em: <https://bit.ly/2ZlraIw〉. Acesso em: 31 mar. 2019.

PROCURADORIA-GERAL DA REPÚBLICA. Ação direta de inconstitucionalidade $\mathrm{n}^{\circ}$ 5.766. Brasília, 24 de agosto de 2017. Disponível em: 〈https://bit.ly/31ZJuUW〉. Acesso em: 31 mar. 2019.

SCHIAVI, Mauro. A reforma trabalhista e o processo do trabalho: aspectos processuais da Lei n. 13.467/17. 1. ed. São Paulo: LTr Editora, 2017. 